\title{
Venous arrangement of the head and neck in humans - anatomic variability and its clinical inferences
}

\author{
SILVA, M. R. M. A. ${ }^{1 *}$, HENRIQUES, J. G. B. ${ }^{1}$, SILVA, J. H. ${ }^{1}$, \\ CAMARGOS, V. R. ${ }^{2}$ and MOREIRA, P. R. ${ }^{1}$
}

\author{
${ }^{1}$ Department of Morphology, Institute of Biological Sciences, Universidade Federal de Minas Gerais - UFMG, \\ Av. Antonio Carlos, 6627, CEP 31920-000, Belo Horizonte, MG, Brazil \\ ${ }^{2}$ Centro Universitário de Belo Horizonte - UniBH, Rua Diamantina, 567, Lagoinha, CEP 31110-320, \\ Belo Horizonte, $\mathrm{MG}$, Brazil \\ *E-mail: micenarm@gmail.com
}

\begin{abstract}
Introduction: The knowledge of morphological variations of the veins of the head and neck is essential for health professionals, both for diagnostic procedures as for clinical and surgical planning. This study described changes in the following structures: retromandibular vein and its divisions, including the relationship with the facial nerve, facial vein, common facial vein and jugular veins. Material and Methods: The variations of the veins were analyzed in three heads, five hemi-heads (right side) and two hemi-heads (left side) of unknown age and sex. Results: The changes only on the right side of the face were: union between the superficial temporal and maxillary veins at a lower level; absence of the common facial vein and facial vein draining into the external jugular vein. While on the left, only, it was noted: posterior division of retromandibular, after unite with the common facial vein, led to the internal jugular vein; union between the posterior auricular and common facial veins to form the external jugular and union between posterior auricular and common facial veins to terminate into internal jugular. The absence of the anterior and posterior divisions of retromandibular vein was observed on both sides of the face. Conclusion: These findings provide relevant informations about important vessels of the head and neck and will contribute to the appropriate clinical and / or surgical planning, aiming at the preservation of important structures.
\end{abstract}

Keywords: anatomic variation, retromandibular vein, facial vein, jugular vein.

\section{Introduction}

Veins are vascular structures that most often present alterations in the drainage pattern when compared to the arteries. Numerous studies have been done on these blood vessels in various parts of the human body, including the head and neck (PRAKASH and BHAGATH, 2007; BALACHANDRA, PADMALATHA, PRAKASH et al., 2012; YANG, GIL, JIN et al., 2012; JOO, FUNAKI, YOSHIOKA et al., 2013; SHETTY, NAYAK, KUMAR et al., 2013; ASSIS, FERNANDES and ARAÚJO, 2014). The standard anatomical report of the veins of the face consists of the union between the maxillary and superficial temporal veins within of the parotid gland with the consequent formation of the retromandibular vein (MEHRA, KAUL and DAS, 2003; CHOUDHARY, SHARMA and SINGH, 2010; SELVI and KUMAR, 2013). This, in turn, is a vessel of considerable importance used as a guide to locate the facial nerve and its branches. The identification of this cranial nerve is specially required in superficial parotidectomy and in reduction of mandibular fractures, considering the real possibility of injury to the nerve (WANG and EISELE, 2012). In normal description, the retromandibular vein is situated between superficial and deep lobes of the parotid gland, being lateral to external carotid artery and medial to the facial nerve (BHATTACHARYYA and VARVARES, 1999; CHOUDHARY, SHARMA and SINGH, 2010; TOURÉ and VACHER, 2010; JOO, FUNAKI, YOSHIOKA et al., 2013). However, results from an anomalous relationship between facial nerve and retromandibular vein have been shown (BHATTACHARYYA and VARVARES, 1999). Morphologically, the retromandibular vein shows the anterior and posterior divisions. The first division joins with the facial vein, inferior and anterior of the angle of mandible, resulting in the formation of common facial vein and subsequent drainage into internal jugular vein. The second division, the posterior branch, joins with posterior auricular vein to form external jugular vein with oblique and superficial trajectory on sternocleidomastoid muscle. Then, the external jugular vein pierces the cervical deep fascia in the posterior triangle of the neck to drain into subclavian vein (CHOUDHARY, SHARMA and SINGH, 2010).

The facial vein or anterior facial vein, another relevant anatomical element, starts as angular vein from the confluence of the supraorbital and supratrochlear veins at the middle third of the face. During this course, it passes under the orbicularis oculi and zygomatics muscles, and buccal fat pad, and over the buccinators muscle and anterior to the masseter muscle. Then, the vein crosses the body of the mandible region, superficially to the submandibular gland. Normally, near the angle of the mandible occurs the union between facial vein and anterior portion of retromandibular vein with formation of the common facial vein. The literature has reported the presence of deviations in the facial vein and common facial vein, although variations in the latter vessel are less frequent (SELVI and KUMAR, 2013). 
Various applicability may be mentioned by proper knowledge of drainage patterns of the veins of the head and neck. The presence of morphological variations is determinant for health professionals such as anatomists, anesthetists, oral and maxillofacial surgeons, clinicians and radiologists (GUPTA, TULI, CHOUDHARY et al., 2003; SCHUMMER, SCHUMMER, BREDLE et al., 2004; CHAUHAN, RANI, CHOPRA et al., 2011). The external veins of the head and neck are of particular interest in the use as patches for surgery to remove plaque buildup in the carotid arteries; for oral reconstruction surgeries, where the creation of a vascular supply by anastomosis is crucial and in this case is recognized the participation of the facial vein (SABHARWAL and MUKERJEE, 1998).

The system of the jugular veins is increasingly used for cannulation (MATHERS, SMITH and FRANKEL, 1992). The introduction of catheters is indicated in patients to administration of medications and solutions; invasive hemodynamic monitoring; conduct medical examinations (angiography and angioplasty, for example); hemodialysis and hemofiltration (GUPTA, TULI, CHOUDHARY et al., 2003; ASOUHIDOU, NATSIS, ASTERI et al., 2008; CHOUDHARY, SHARMA and SINGH, 2010). Besides the use of internal and external jugular veins for introductions of catheters, the facial vein is also an option for central venous access, whose research of its varying venous patterns is necessary to prevent the disruption of vessels and consequent bleeding (NAGASE, KOBAYASHI, SEKIYA et al., 1997; GUPTA, TULI, CHOUDHARY et al., 2003; MEHRA, KAUL and DAS, 2003). Although deviations in the course and termination of the superficial veins of the head and neck are relative common, few changes have been mentioned on the retromandibular vein.

Given the above, the present anatomic study reports some cases of deviation from the normal pattern in the venous system of head and neck, which will contribute to minimize errors and ensure success of clinical procedures performed in these regions. This study described changes in the retromandibular vein and its divisions, including the relationship with the facial nerve, facial vein, common facial vein and jugular veins.

\section{Material and Methods}

Heads and hemi-heads embalmed in formalin used during the classes for students of Dentistry in the Department of Morphology of Federal University of Minas Gerais, Belo Horizonte, Brazil, were evaluated in this study. To the data collection procedure was not necessary the approval by the institutional ethical committee, since the research was conducted in a human anatomy laboratory, keeping the ethical principles and respect for the cadavers.

The materials for the present research included three heads, five hemi-heads on the right side and two hemi-heads on the left side. Anatomic variations in the veins of the head and neck were evaluated and described. These variations were found in a formalin embalmed pieces of both sexes with different age. It is important to mention that the impossibility of analyzing the right and left hemi-heads of the same cadaver was due to the fact that one side of the pieces were already dissected to observe the deeper structures, without the preservation of veins covered in this work. This observation was also present in much of the cadaveric material available in the anatomy laboratory, justifying the small sample size used in this work. Photographs were obtained and drawings were provided.

\section{Results}

Below are detailed the more frequent pattern of the veins of the head and neck (Figure 1) and the changes in the distribution of these veins observed in this study. Note that in all photographed heads and hemi-heads, the parotid gland was removed.

In Figures 2 and 3 is shown the superficial temporal vein (STV) united with the maxillary vein (MV) at a lower level between angle of the mandible and sternocleidomastoid muscle (ECM). This anatomical variation was present only in one hemi-head on the right side. Also noted the formation of a ring from the temporofacial division of the facial nerve (FN) surrounding the STV.

The absence of anterior (ADRMV) and posterior (PDRMV) divisions of retromandibular vein (RMV) was also identified. This morphological alteration was present in four cases on the right side and in one case on the left side (Figure 4). The union of posterior auricular vein (PAV) with the common facial vein (CFV) to form the external jugular vein (EJV) was present only in one hemi-head on the right side (Figure 4).

In Figure 5 is possible observe that the PDRMV joined with the CFV, terminating into internal jugular vein (IJV). This alteration was present only in one hemi-head on the left side.

A total of four hemi-heads on the right side had the absence of CFV (Figure 6). However, this was not noticed in hemi-heads on the left side. Additionally, the facial vein (FV) drained into EJV (Figure 7) was found only in three hemi-heads on the right side. It was further observed the union of PAV with the CFV and terminating into IJV only in one hemi-head on the left side (Figure 8).

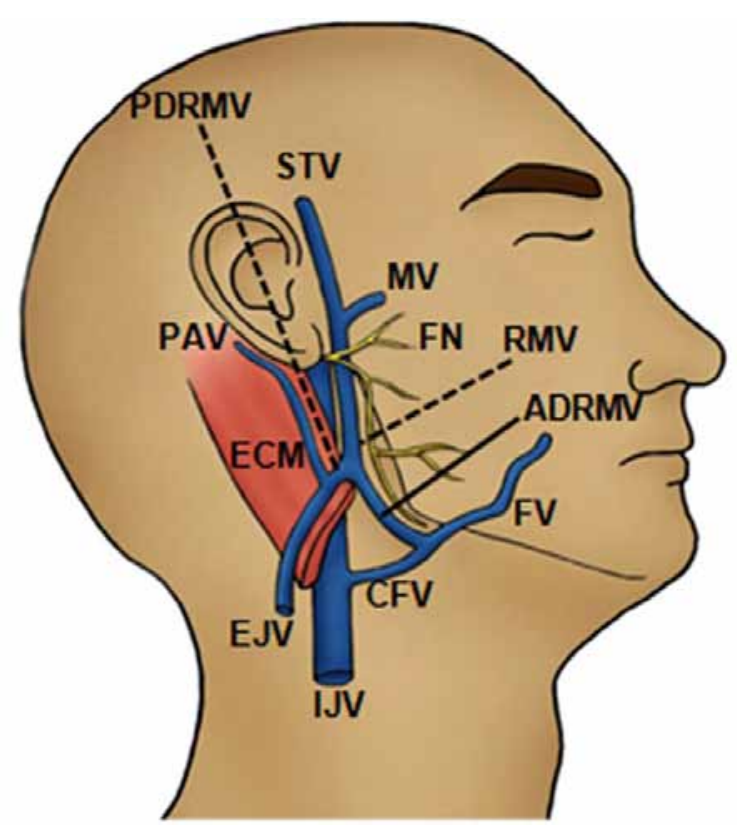

Figure 1. Schematic drawing of the more frequent pattern of the veins of the head and neck. STV: superficial termporal vein, MV: maxillary vein, RMV: retromandibular vein, $\mathrm{FN}$ : facial nerve, ADRMV: anterior division of retromandibular vein, PDRMV: posterior division of retromandibular vein, FV: facial vein, CFV: common facial vein, IJV: internal jugular vein, PAV: posterior auricular vein, EJV: external jugular vein, ECM: sternocleidomastoid muscle. 

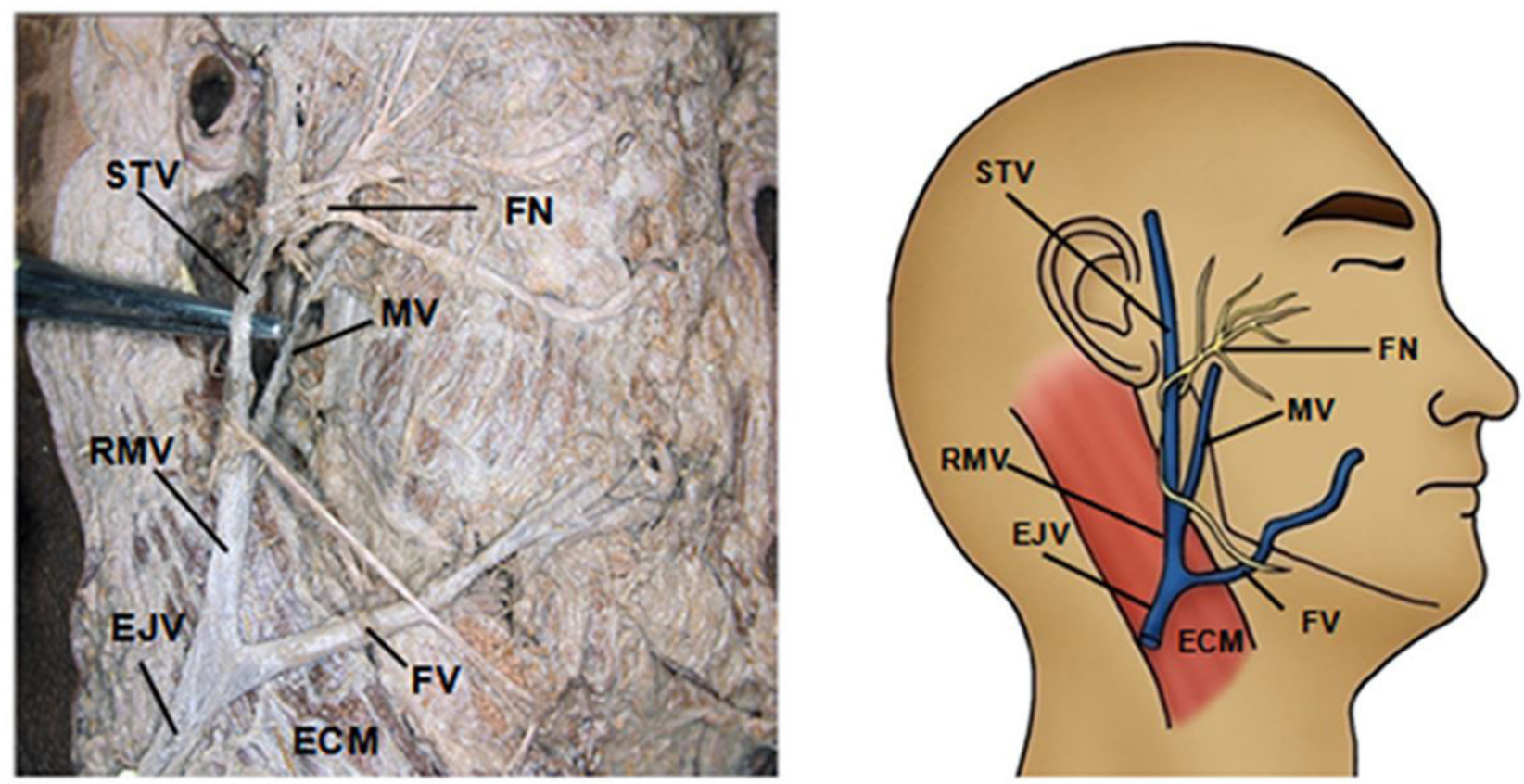

Figure 2. Lateral view of the dissected right side of the head and neck. Superficial temporal vein (STV) united with the maxillary vein $(\mathrm{MV})$ at a lower level between angle of mandible and sternocleidomastoid muscle (ECM). RMV: retromandibular vein, FV: facial vein, EJV: external jugular vein, FN: facial nerve.
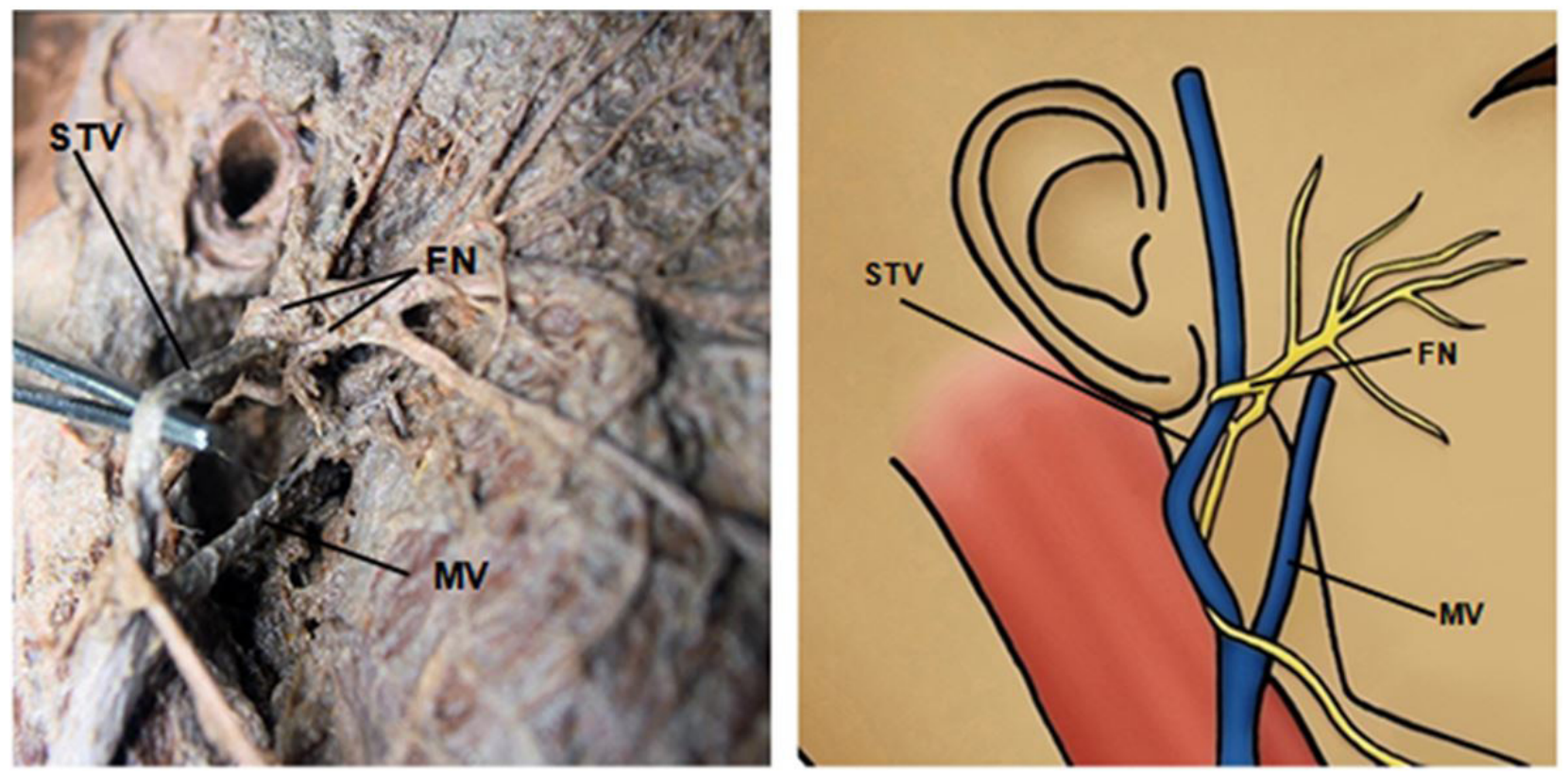

Figure 3. Higher increase of the lateral view of the dissected right side of the head and neck identified in the previous figure. Observe the formation of a ring from the temporofacial division of facial nerve (FN) surrounding the superficial temporal vein (STV). MV maxillary vein.

\section{Discussion}

Often the venous drainage system of the human body has variability in its morphological characteristics such as distribution, size and location of the veins. Interestingly, attention has been directed to report the presence of these changes in the regions of the head and neck, which are crucial since conducting diagnostics, examination and surgical planning, justifying the real need of the anatomical knowledge of the veins and their variations.
Generally, the RMV is formed by the union of the STV and the MV at a higher level into the parotid gland, near the neck of the mandible (PRAKASH and BHAGATH, 2007). In this study, it was possible to observe that the union between the tributary veins of the RMV occurred at a lower level between angle of the mandible and ECM (Figure 2). This finding has not yet reported in the literature, but it is of considerable importance since, during surgical procedures, the presence of an undesirable bleeding may occur due to a greater exposure 

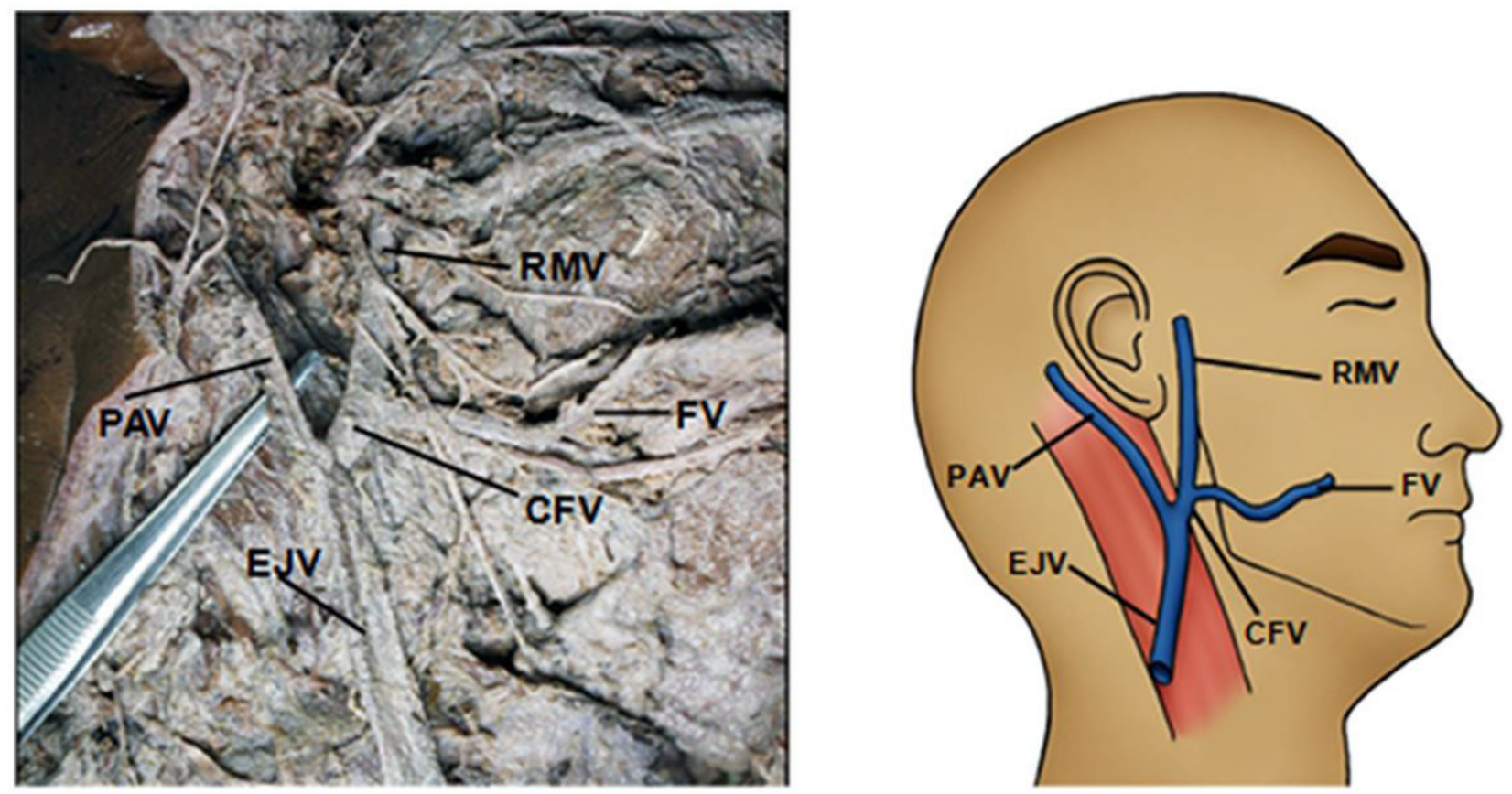

Figure 4. Lateral view of the dissected right side of the head and neck. Observe the undivided retromandibular (RMV) and union between posterior auricular vein (PAV) and common facial vein (CFV) to form the external jugular vein (EJV). FV: facial vein.
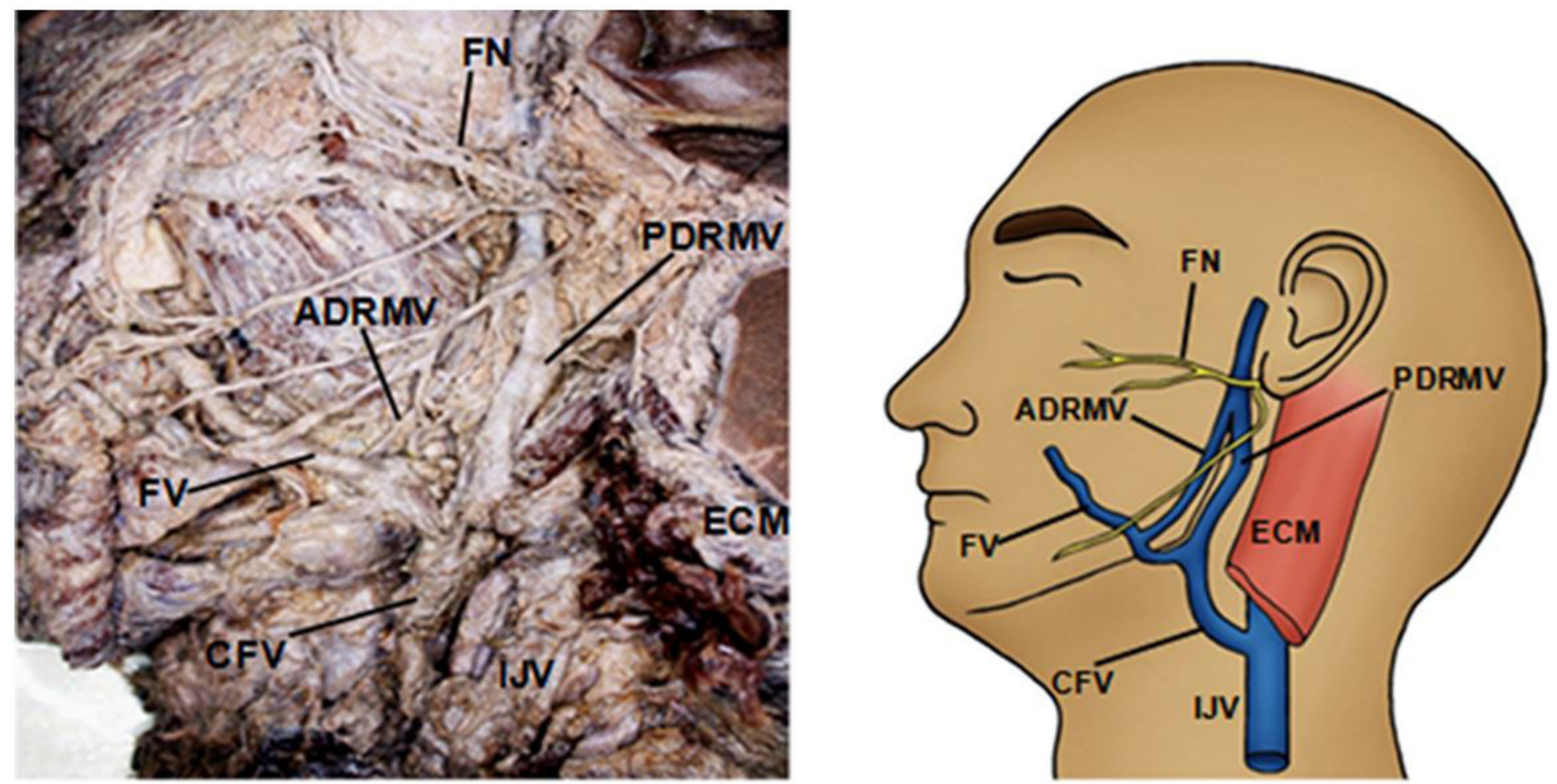

Figure 5. Lateral view of the dissected left side of the head and neck. Posterior division of retromandibular vein (PDRMV) joined with common facial vein (CFV), terminating into internal jugular vein (IJV). FN: facial nerve, ADRMV: anterior division of retromandibular vein, FV: facial vein, ECM: sectioned sternocleidomastoid muscle.

of the veins into the parotid gland (NAGASE, KOBAYASHI, SEKIYA et al., 1997).

Additionally, variation in the anatomical relationship between the RMV and the FN with the formation of a ring from the temporofacial division of the FN surrounding the STV has also been reported. The results of the actual work (Figure 3) are same from the observations of Alzahrani and Alqahtani (2012), during removal of the Warthin's tumour of the parotid gland in a male. However, these authors also described that cervicofacial division of FN passed through a ring in RMV. Furthermore, these results are different from the observations of Touré and Vacher (2010), who described that the RMV was medial to the FN trunk and its branches in $65,2 \%$ of cases ( 86 parotids glands). In this same research, the authors related that the RMV was lateral to the temporofacial division only in $3 \%$ of cases ( 4 parotids glands), but there 

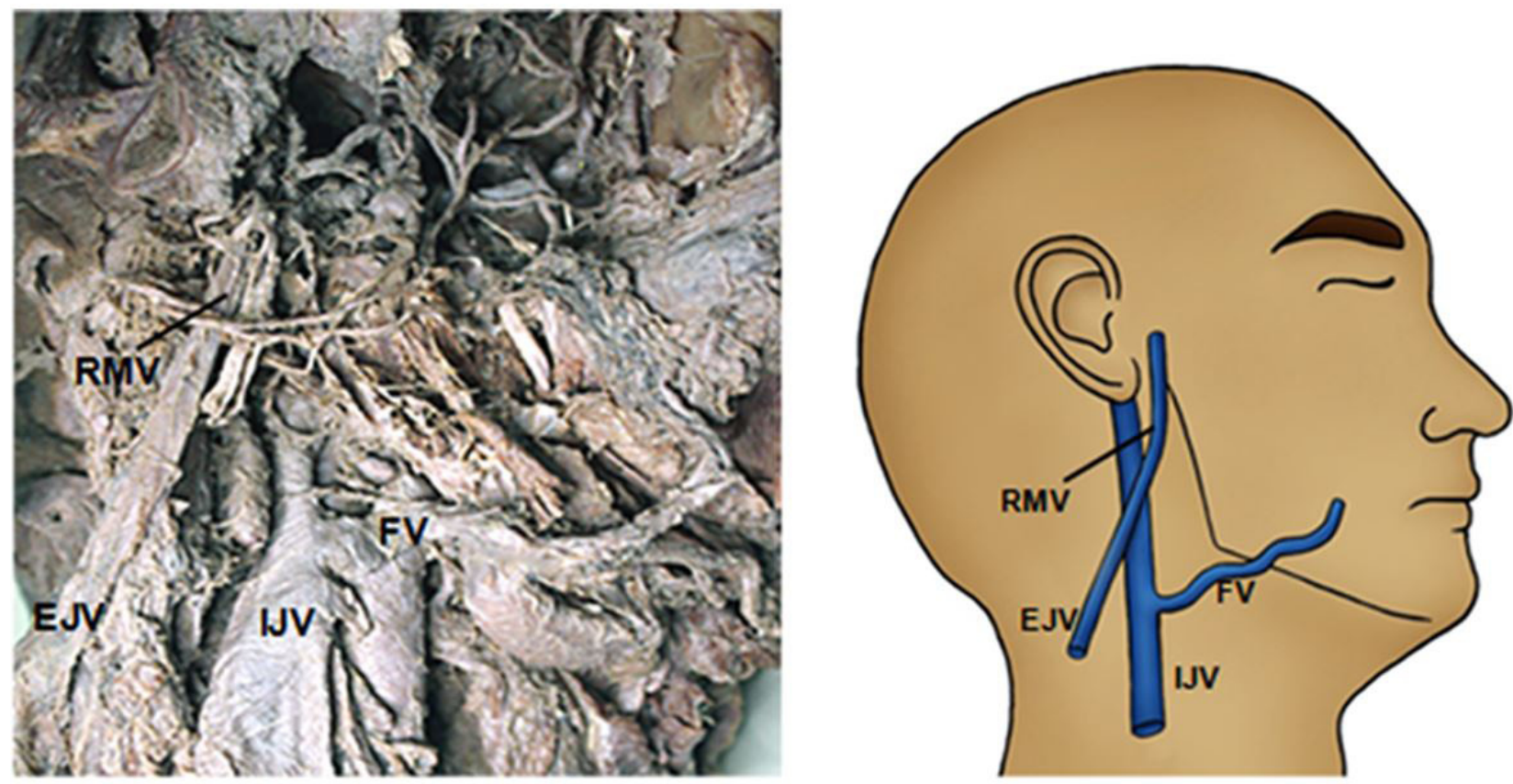

Figure 6. Lateral view of the dissected right side of the head and neck. Termination of facial vein (FV) into internal jugular vein (IJV) and absence of common facial vein. RMV: retromandibular vein, EJV: external jugular vein.
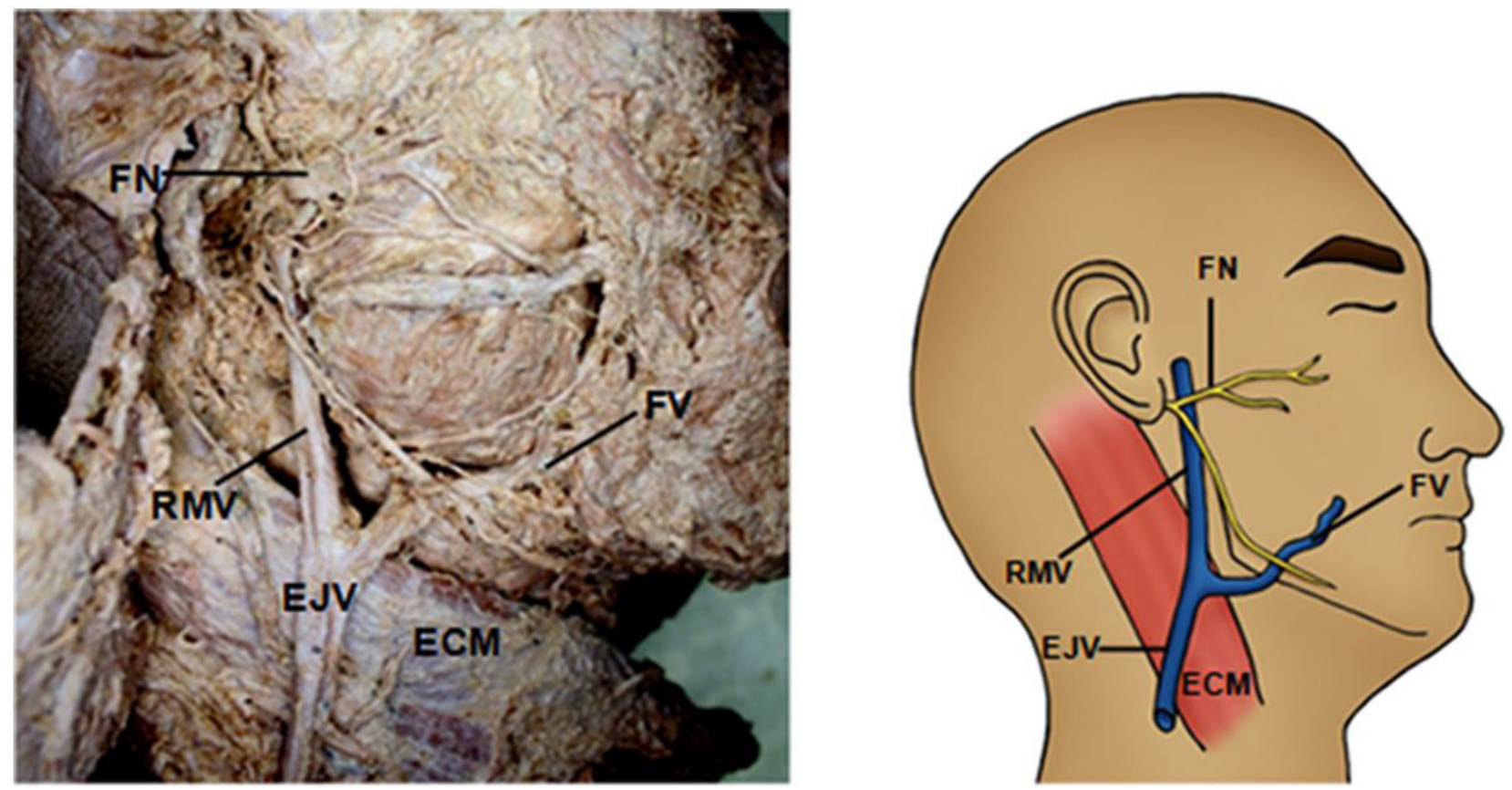

Figure 7. Lateral view of the dissected right side of the head and neck. Facial vein (FV) drained into external jugular vein (EJV). FN: facial nerve, RMV: retromandibular vein, ECM: sternocleidomastoid muscle.

was no formation of a ring. The literature reveals that an important clinical implication during a parotidectomy is the FN injury and, in this context, the RMV has been described by some authors as a relevant anatomical parameter for superficial or deep location of parotid tumour in relation the FN (BHATTACHARYYA and VARVARES, 1999; TOURÉ and VACHER, 2010; ALZAHRANI and ALQAHTANI, 2012). Interestingly, the data presented, in this recent study, reveal that abnormal patterns of the tributaries of the RMV, particularly the STV should be taken into consideration prior to any surgical intervention, corroborating with Kawakami, Tsukada and Taniguchi (1994).

Some important considerations must also be made in relation to the ADRMV and PDRMV divisions of the RMV. Mehra, Kaul and Das (2003), during routine dissection in an adult male cadaver aged 52 years observed the lack of 

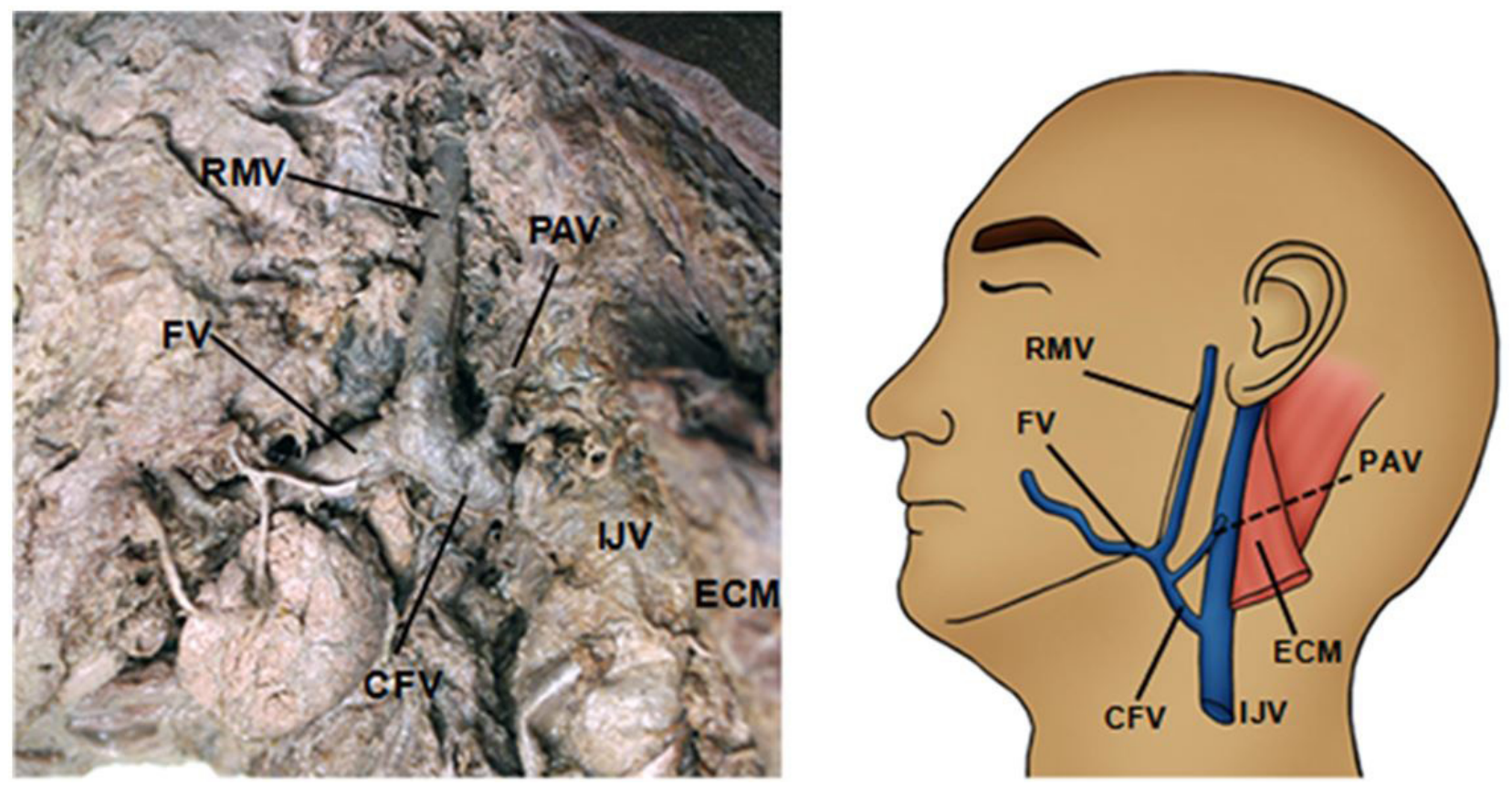

Figure 8. Lateral view of the dissected left side of the head and neck. Union of posterior auricular vein (PAV) with the common facial vein $(\mathrm{CFV})$ and terminating into internal jugular vein (IJV). RMV: retromandibular vein, FV: facial vein, ECM: sternocleidomastoid muscle.

these divisions of the RMV on the right side of the face. This observation was also shared by Balachandra, Padmalatha, Prakash et al. (2012), on the right side of a male cadaver and by Selvi and Kumar (2013) in one cadaver, assuming a total of 32 cadavers dissected, corroborating with the findings of the present study (Figure 4), which reinforces the literature on the prevalence of venous alterations on the right side. Although these authors demonstrated the absence of these variations on the left side of the face, the current research revealed the presence of morphological alteration in one case on the left side, being in agreement with D'Silva, Pulakunta and Potu (2008). Choudhary, Sharma and Singh (2010), in a case report, found a bilateral variation in the undivided trunk of RMV.

Likewise that the literature reports the presence of undivided RMV, it is clear that its two divisions can drain to a venous trunk in common. The results obtained in this research showed that ADRMV joined with $\mathrm{FV}$, resulting in formation of $\mathrm{CFV}$, which, after receiving the PDRMV, drained immediately into IJV (Figure 5). This finding is a rare case of venous drainage of head and neck and it corroborates with the observation first described by Selvi and Kumar (2013) regarding the union between PDRMV and CFV. On the other hand, Chauhan, Rani, Chopra et al. (2011), in an interesting research, reported that both ADRMV as PDRMV ended in a common trunk, that they will not dubbed as CFV, but as V2 venous trunk with the subsequent formation of EJV. Shankar, Chandrashekar and Chowdapurkar (2012), in turn, reported that the ADRMV formed a single vessel from its junction with PDRMV, terminating into the left subclavian vein and not in the jugular venous system. In contrast, on the right side of this same cadaver, the IJV received directly the PDRMV. It is worth noting that other authors showed variations in venous drainage of ADRMV, such as Selvi and Kumar (2013) that demonstrated the union between this vein and EJV. However, this observation was not found in the results of this research.

In this study was found a total of four hemi-heads on the right side with absence of CFV (Figure 6) and FV draining into the EJV in three hemi-heads on the right side (Figure 7). Usually, the union of the ADRMV and FV forms the CFV with termination into the IJV. However, several authors have noted the absence of the CFV, which contributed to a modified venous drainage. Gupta, Tuli, Choudhary et al. (2003) related that FV terminated in the EJV in 16 sides (five were of the right and eleven of the left side) unilaterally in 14 cadavers and bilaterally in one, without the formation of the CFV, being the latter finding also reported by Choudhary, Sharma and Singh (2010). This different pattern of variation in the FV drainage was also described on the left side of head and neck by D'Silva, Pulakunta and Potu (2008) and Chauhan, Rani, Chopra et al. (2011). Interestingly, in the study done by Pai, Vadgaonkar, Prabhu et al. (2008), 7,7\% of 52 adult cadavers dissected (eight out of 104 sides) showed a similar pattern of termination of the FV. On seven sides, there was formation of the CFV, but this ended into the EJV, while that on the right side of one cadaver the EJV received the FV directly. This anomalous termination of the FV has sparked interest in the authors to verify the embryological basis of this drainage and a plausible explanation is the persistence of communication between the primitive linguofacial veins with EJV after birth, leading to retention of the connection between the FV and superficial jugular vein (GUPTA, TULI, CHOUDHARY et al., 2003).

In addition to the changes mentioned above, this study provided interesting information about the PAV drainage, being the first to demonstrate the union between the CFV and the PAV to form the EJV. Selvi and Kumar (2013) described the union between the PAV and the CFV terminating in the 
IJV, corroborating with data demonstrated in this research (Figure 8). One suggested explanation for this is that an impaired development of the EJV contributes to the PAV remains as a single channel and drain directly into the IJV.

Undoubtedly, the changes reported in this study reinforce the need for adequate knowledge of the venous drainage system of the head and neck, not only the normal anatomical aspect but also morphological variations. Understanding these relations is a crucial step towards a relevant clinical and/ or surgical planning, which will lead to a clinical intervention with minimal chance of injury to the venous blood system, as well as their adjacent structures.

Acknowledgements: The authors would like to express immense gratitude to cadavers donors and the Department of Morphology, which made possible the realization of this study.

\section{References}

ALZAHRANI, FR. and ALQAHTANI, KH. The facial nerve versus the retromandibular vein: a new anatomical relationship. Head \& Neck Oncology, 2012, vol. 4, p. 82-85.

ASOUHIDOU, I., NATSIS, K., ASTERI, T., SOUNTOULIDES, P., LASIS, $\mathrm{K}$. and TSIKARAS, P. Anatomical variation of the left internal Jugular vein: clinical significance for an anaesthesiologist. European Journal of Anaesthesiology, 2008, vol. 25, n. 4, p. 314-318. http:// dx.doi.org/10.1017/S0265021508003700. PMid:18289445.

ASSIS, TO., FERNANDES, LS. and ARAÚJO, JC. Anatomical description of double left suprarenal vein and its implications on renal transplantation surgerires. Journal of Morphological Science, 2014 , vol. 31, n. 3, p. 156-158. http://dx.doi.org/10.4322/jms.058413.

BALACHANDRA, N.,PADMALATHA, K., PRAKASH, BS. and RAMESH, BR. Variation of the veins of the head and neck - external jugular vein and facial vein. International Journal of Anatomical Variations, 2012, vol. 5, p. 99-101.

BHATTACHARYYA, N. and VARVARES, MA. Anomalous relationship of the facial nerve and the retromandibular vein: a case report. Journal of Oral and Maxillofacial Surgery, 1999, vol. 57, n. 1, p. 75-76. http:// dx.doi.org/10.1016/S0278-2391(99)90639-0. PMid:9915401.

CHAUHAN, NK., RANI, A., CHOPRA, J., RANI, A., SRIVASTAVA, AK. and KUMAR, V. Anomalous formation of external jugular vein and its clinical implication. National Journal of Maxillofacial Surgery, 2011, vol. 2, n. 1, p. 51-53. http://dx.doi.org/10.4103/09755950.85854. PMid:22442610.

CHOUDHARY, S., SHARMA, AK. and SINGH, H. Undivided retromandibular vein continuing as external jugular vein with facial vein draining into it: an anatomical variation. JK Science, 2010, vol. 12, p. 203-204.

D'SILVA, SS., PULAKUNTA, T. and POTU, BK. Termination of the facial vein into the external jugular vein: an anatomical variation. Jornal Vascular Brasileiro, 2008, vol. 7, p. 174-175.

GUPTA, V., TUli, A., CHOUDHARY, R., AGARWAL, S. and MANGAL, A. Facial vein draining into external jugular vein in humans: its variations, phylogenetic retention and clinical relevance. Surgical and Radiologic Anatomy, 2003, vol. 25, n. 1, p. 36-41. http://dx.doi.org/10.1007/s00276-002-0080-z. PMid:12819948.

JOO, W., FUNAKI, T., YOSHIOKA, F. and RHOTON JUNIOR, AL. Microsurgical anatomy of the infratemporal fossa. Clinical Anatomy,
2013, vol. 26, n. 4, p. 455-469. http://dx.doi.org/10.1002/ ca.22202. PMid:23355316.

KAWAKAMI, S., TSUKADA, S. and TANIGUCHI, W. The superficial temporal and retromandibular veins as guides to expose the facial nerve branches. Annals of Plastic Surgery, 1994, vol. 32, n. 3, p. 295 299. http://dx.doi.org/10.1097/00000637-199403000-00012. PMid:8192391.

MATHERS, LH., SMITH, DW. and FRANKEL, L. Anatomic considerations in placement of central venous catheters. Clinical Anatomy, 1992, vol. 5, n. 2, p. 89-106. http://dx.doi.org/10.1002/ ca.980050202.

MEHRA, S., KAUL, JM., and DAS, S. Unusual venous drainage pattern of face: a case report. Journal of the Anatomical Society of India, 2003, vol. 52, p. 64-65.

NAGASE, T., KOBAYASHI, S., SEKIYA, S. and OHMORI, K. Anatomic evaluation of the facial artery and vein using color Doppler ultrasonography. Annals of Plastic Surgery, 1997, vol. 39, n. 1, p. 64-67. http://dx.doi.org/10.1097/00000637-199707000-00011. PMid:9229095.

PAI, M., VADGAONKAR, R., PRABHU, L. and SHETTY, P. The different termination patterns of the facial vein - a cadaveric study. Firat Medial Journal, 2008, vol. 13, p. 32-34.

PRAKASH, BB., and BHAGATH, KP. A rare termination of left common facial vein into left subclavian vein: a case report. International Journal of Morphology, 2007, vol. 25, p. 555-556.

SABHARWAL, P. and MUKERJEE, D. Autogenous common facial vein or external jugular vein patch for carotid endarterectomy. Cardiovascular Sugery, 1998, vol. 6, n. 6, p. 594-597. http://dx.doi. org/10.1016/S0967-2109(98)00084-2. PMid:10395262.

SCHUMMER, W., SCHUMMER, C., BREDLE, D. and FROBER, $\mathrm{R}$. The anterior jugular venous system: variability and clinical impact. Anesthesia and Analgesia, 2004, vol. 99, n. 6, p. 1625-1629. http:// dx.doi.org/10.1213/01.ANE.0000138038.33738.32. PMid:15562044.

SELVI, GP., and KUMAR, BS. Variations in the venous drainage pattern of face and neck. International Journal of Pharma and Bio Sciences, 2013, vol. 4, p. 150-154.

SHANKAR, VV., CHANDRASHEKAR, D., and CHOWDAPURKAR, $S$. Bilateral anatomical variations in the formation, communication and the termination of the retromandibular vein. Journal of Clinical and Diagnostic Research, 2012, vol. 6, p. 286-1288.

SHETTY, SD., NAYAK, S., KUMAR, N., MARPALLI, S., and MADAHV, V. Unusual veins in the neck - a case report. Journal of Morphological Science, 2013, vol. 30, p. 203-205.

TOURÉ, G. and VACHER, C. Relations of the facial nerve with the retromandibular vein: anatomic study of 132 parotid glands. Surgical and Radiologic Anatomy, 2010, vol. 32, n. 10, p. 957-961. http:// dx.doi.org/10.1007/s00276-010-0674-9. PMid:20473672.

WANG, SJ. and EISELE, DW. Parotidectomy-anatomical considerations. Clinical Anatomy, 2012, vol. 25, n. 1, p. 12-18. http://dx.doi. org/10.1002/ca.21209. PMid:21671284.

YANG, HJ., GIL, YC., JIN, JD., CHO, H., KIM, H. and LEE, HY. Novel findings of the anatomy and variations of the axillary vein and its tributaries. Clinical Anatomy, 2012, vol. 25, n. 7, p. 893-902. http://dx.doi.org/10.1002/ca.22086. PMid:22623347.

Received August 15, 2014 Accepted July 6, 2016 